\title{
Componentes de produção e rendimento de soja em função da época de dessecação e do manejo em pós-emergência
}

\author{
Components of production and soybean yield in relation to the time of burndown \\ and of management in post-emergency
}

\section{Guilherme Braga Pereira Braz ${ }^{1}$, Gabriel Martins Cassol ${ }^{2}$, Gustavo Adolfo Pazzetti Ordoñez ${ }^{3}$, Gustavo André Simon ${ }^{3}$, Sérgio de Oliveira Procópio ${ }^{4}$, Antonio Mendes de Oliveira Neto ${ }^{5}$, Wander Cruvinel Ferreira Filho ${ }^{6}$, Hugo de Almeida Dan ${ }^{5}$}

Resumo - Objetivando avaliar os componentes de rendimento e a produtividade da cultura da soja em resposta à época de dessecação e do manejo realizado em pós-emergência em cultivares de soja transgênica e convencional, instalou-se na área do Centro Tecnológico da COMIGO, o presente experimento. $\mathrm{O}$ delineamento experimental utilizado foi o de blocos casualizados em arranjo fatorial $2 \times 7$, com oito repetições. O primeiro fator correspondeu a épocas de dessecação antecedendo a semeadura da soja, realizada 15 e 1 dia antes da semeadura. $\mathrm{O}$ segundo fator constituiu de sete manejos pós-emergentes, sendo eles descritos a seguir: 1 - BRS-GO Luziânia $\mathrm{RR}^{\circledR}$ com capina manual; 2 - BRS-GO Luziânia $\mathrm{RR}^{\circledR}$ sem nenhum controle; 3 - BRS-GO Luziânia RR ${ }^{\circledR}$ aplicação de glyphosate aos 15 DAE; 4 - BRS-GO Luziânia RR ${ }^{\circledR}$ aplicação de glyphosate aos 30 DAE; 5 - BRS-GO Luziânia RR ${ }^{\circledR}$ aplicação de glyphosate aos 15 e 30 DAE; 6 - BRS-GO Luziânia com controle químico padrão da região; e 7 - BRS-GO Luziânia, com capina manual. Todas as parcelas foram capinadas ao longo do ciclo da cultura, exceto a testemunha sem nenhum controle. As variáveis avaliadas foram: altura de plantas na colheita, altura de inserção da primeira vagem, número de vagens com 1, 2 e 3 grãos, número total de vagens por planta, massa de cem grãos e rendimento de grãos. Os resultados permitiram constatar que: os herbicidas imazethapyr $\left(30 \mathrm{~g} \mathrm{ha}^{-1}\right)+$ lactofen $\left(84 \mathrm{~g} \mathrm{ha}^{-1}\right)+$ chlorimuron-ethyl $\left(80 \mathrm{~g} \mathrm{ha}^{-1}\right)+$ haloxyfop-methyl $\left(72 \mathrm{~g} \mathrm{ha}^{-1}\right)$ utilizados em soja convencional causaram menor crescimento das plantas de soja e menor altura de inserção da primeira vagem; o número de vagens por planta não sofreu influência de nenhum dos tratamentos avaliados; a massa de cem grãos e a produtividade da soja foi reduzida quando se realizou o manejo antecipado na dessecação (15 DAS) e quando não se adotou nenhum manejo em pós-emergência.

Palavras-chave: Glycine max, transgenia, controle químico.

\footnotetext{
Abstract - Aiming to evaluate the yield and productivity of soybean crop in response to burndown time and herbicide application in post-emergence in conventional and transgenic genotypes, the area of Technological Center COMIGO, was used to conduct this study. The

${ }^{1}$ Mestrando do Programa de Pós-Graduação em Agronomia da Universidade Estadual de Maringá (UEM/NAPD), Av. Colombo 5790, 87020-900, Maringá, PR. Email: <guilhermebrag@ gmail.com>;

${ }^{2}$ Engenheiro Agrônomo da Empresa ACL agrícola, Rio Verde - GO;

${ }^{3}$ Professores da Faculdade de Agronomia da FESURV - Universidade de Rio Verde;

${ }^{4}$ Pesquisador, Embrapa Tabuleiros Costeiros, 49025-040, Aracaju - SE;

${ }_{6}^{5}$ Alunos do Programa de Pós-Graduação em Agronomia da Universidade Estadual de Maringá (UEM/NAPD);

${ }^{6}$ Pesquisador do Centro Tecnológico Comigo (CTC).
} 
experimental design was a randomized complete block in factorial arrangement $2 \times 7$, adopting eight repetitions. The first factor corresponded to burndown times before seeding, performed 15 and 1 day before sowing (DBS). The second factor was constituted by seven managements postemergent, described as follow: 1 - BRS-GO Luziânia $\mathrm{RR}^{\circledR}$ without chemical control with manual weeding; 2 - BRS-GO Luziânia RR ${ }^{\circledR}$ uncontrolled post-emergence; 3 - BRS-GO Luziânia RR ${ }^{\circledR}$ glyphosate application at 15 DAE; 4 - BRS-GO Luziânia RR ${ }^{\circledR}$ glyphosate application at 30 DAE; 5 - BRS-GO Luziânia RR ${ }^{\circledR}$ glyphosate application at 15 and 30 DAE; 6 - BRS-GO Luziânia with chemical control; and 7 - BRS-GO Luziânia without chemical control with manual weeding. All plots were manual weeding along the crop cycle, except those which were allocated to Treatment 02. Variables evaluated were: plant height at harvest, height of first pod, number of pods with 1 , 2 and 3 seeds, total number of pods per plant, weight of one hundred grains and yield. The results allow the conclusion that: imazethapyr $\left(30 \mathrm{~g} \mathrm{ha}^{-1}\right)+$ lactofen $\left(84 \mathrm{~g} \mathrm{ha}^{-1}\right)+$ chlorimuron-ethyl $(80$ $\left.\mathrm{g} \mathrm{ha}^{-1}\right)+$ haloxyfop-methyl $\left(72 \mathrm{~g} \mathrm{ha}^{-1}\right)$ herbicides used on conventional soybeans caused smaller growth of soybean plants and smaller height of first pod; number of pods per plant was not affected by all treatments; the weight of one hundred grains and soybean productivity was reduced when it was realized early management (15 DBS) and none management in postemergence was adopted.

Keywords: Glycine max, transgenic, chemical control.

\section{Introdução}

Dentro das práticas culturais empregadas para a obtenção de maiores produtividades da soja, o manejo de plantas daninhas é uma operação fundamental para a manutenção do potencial produtivo desta cultura. A competição com as plantas daninhas afeta o desenvolvimento da soja devido a concorrência no aporte de recursos do meio, tais como água, luz e nutrientes, fazendo com que haja uma redução na disponibilidade desses para a cultura, resultando assim em redução na produtividade de grãos (Silva et al., 2008).

Visando reduzir os problemas referentes à matocompetição, o controle químico se destaca como uma excelente estratégia de manejo, devido às características de praticidade, eficiência e rapidez na execução em grandes áreas (Gazziero et al., 2004), sendo o principal método de controle de plantas daninhas utilizado na cultura da soja (Arruda et al., 2001).
Dentre os herbicidas mais utilizados para a dessecação pré-semeadura, destaca-se o glyphosate, por possuir reconhecida eficácia e amplo espectro de controle de plantas daninhas (Dvoranen et al., 2008). Com relação à época de utilização do glyphosate na dessecação, diversos trabalhos têm relatado que a melhor época de se utilizar racionalmente este produto é de 15 a 20 dias antes da semeadura, fazendo no dia da semeadura uma aplicação de algum herbicida de contato, eliminando então um novo fluxo de plantas daninhas (Nunes et al., 2009; Constantin et al., 2009). Entretanto, muitos produtores optam pela aplicação do glyphosate no dia da semeadura, no conhecido sistema "aplique-plante", com o intuito de otimizar tempo e maximizar a utilização do maquinário (Oliveira Jr et al., 2006).

O sucesso da dessecação pré-semeadura é importantíssimo para o estabelecimento inicial da cultura da soja, onde esta encontrará condições propícias para o seu desenvolvimento (Freitas et al., 2006). Quando se opta por variedades de soja precoce, e a 
dessecação for eficiente, o manejo de plantas daninhas em pós-emergência é bastante facilitado, e, em alguns casos se encerra o controle de plantas daninhas com apenas uma ou nenhuma aplicação em pós-emergência.

Assim como a dessecação présemeadura, o manejo de plantas daninhas em pós-emergência é outra ferramenta que assegura a produtividade da soja contra os danos ocasionados pela competição com as plantas daninhas. Todavia, a utilização de herbicidas em pós-emergência deve ser analisada com cuidado, pois como se trata de uma aplicação direta nas plantas, é necessário saber a respeito da seletividade destes sobre o desenvolvimento e rendimento da cultura (Petter et al., 2007).

Dentro deste contexto, o objetivo deste trabalho foi verificar o efeito da época da dessecação pré-semeadura com glyphosate e diferentes manejos pós-emergentes sobre os componentes de produção e rendimento da cultura da soja convencional e transgênica.

\section{Material e métodos}

O experimento foi conduzido na fazenda experimental da Cooperativa Agroindustrial dos Produtores Rurais do

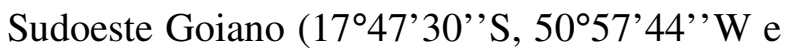
altitude de $770 \mathrm{~m}$ ), localizada no município de Rio Verde - GO. O solo da área experimental é classificado como Latossolo Vermelho distroférrico. O período de condução do experimento foi de 04/11/2008 a 29/03/2009. Foi cultivado anteriormente na área experimental milho em condição de safrinha. Realizou-se coleta de amostras de solo para sua caracterização química (Tabela 01).

Tabela 01. Resultado da análise química do solo presente na área experimental. Rio Verde - GO, 2008/2009.

\begin{tabular}{|c|c|c|c|c|c|c|c|}
\hline \multirow[b]{2}{*}{ Profundidade } & \multirow{2}{*}{$\begin{array}{l}\mathrm{CaCl}_{2} \\
\mathrm{pH}\end{array}$} & \multicolumn{6}{|c|}{ - } \\
\hline & & $\mathrm{Ca}+\mathrm{Mg}$ & $\mathrm{Ca}$ & $\mathrm{Mg}$ & $\mathrm{Al}$ & $\mathrm{H}+\mathrm{Al}$ & $\mathrm{K}$ \\
\hline 0 à $10 \mathrm{~cm}$ & 5,38 & 3,94 & 3,07 & 0,87 & 0,02 & 2,85 & 0,36 \\
\hline \multirow[t]{2}{*}{10 à $20 \mathrm{~cm}$} & 5,21 & 2,98 & 2,41 & 0,57 & 0,03 & 2,38 & 0,16 \\
\hline & \multicolumn{3}{|c|}{------g dm ${ }^{-3}$} & $\mathrm{~g} \mathrm{dm}^{-3}$ & \multicolumn{2}{|c|}{-----cmolc $\mathrm{dm}^{-3}-----$} & $\%$ \\
\hline Profundidade & $\mathrm{K}$ & Pmel & $\mathrm{S}$ & M.O. & SB & CTC & V \\
\hline 0 à $10 \mathrm{~cm}$ & 139,78 & 10,20 & 9,60 & 32,40 & 4,30 & 7,15 & 58,98 \\
\hline \multirow[t]{2}{*}{10 à $20 \mathrm{~cm}$} & 67,45 & 18,40 & 11,03 & 64,05 & 3,15 & 5,53 & 57,44 \\
\hline & \multicolumn{7}{|c|}{---------------------------------------mg dm³ } \\
\hline Profundidade & \multicolumn{2}{|c|}{$\mathrm{B}$} & \multicolumn{2}{|c|}{$\mathrm{Fe}$} & $\mathrm{Mn}$ & $\mathrm{Zn}$ & $\mathrm{Cu}$ \\
\hline 0 à $10 \mathrm{~cm}$ & \multicolumn{2}{|c|}{0,22} & \multicolumn{2}{|c|}{46,79} & $\overline{15,55}$ & 5,43 & 0,49 \\
\hline 10 à $20 \mathrm{~cm}$ & \multicolumn{2}{|c|}{0,23} & \multicolumn{2}{|c|}{40,42} & 13,90 & 4,98 & 0,51 \\
\hline
\end{tabular}

O delineamento experimental utilizado foi o de blocos casualizados em arranjo fatorial 2 x 7, com oito repetições. O fator $\mathrm{A}$ correspondeu a épocas de dessecação présemeadura, sendo 1 - Dessecação 15 dias antes da semeadura e 2 - Dessecação 01 dia antes da semeadura "Aplique e plante". Para o fator B foram adotados sete manejos pós-emergentes, sendo eles descritos a seguir: 1 - BRS-GO Luziânia $\mathrm{RR}^{\circledR}$ com adoção de capina manual; 2 - BRS-GO Luziânia RR ${ }^{\circledR}$ sem nenhum manejo em pós-emergência; 3 - BRS-GO Luziânia $\mathrm{RR}^{\circledR}$ com aplicação de glyphosate aos 15 DAE; 4 - BRS-GO Luziânia RR ${ }^{\circledR}$ com aplicação de glyphosate aos 30 DAE; 5 - BRS-GO Luziânia 
$\mathrm{RR}^{\circledR}$ com aplicação de glyphosate aos 15 e 30 DAE; 6 - BRS-GO Luziânia com adoção de controle químico padrão da região; e 7 - BRSGO Luziânia com adoção de capina manual.

Cada unidade experimental correspondeu a 10 linhas de soja com comprimento de 10 metros, espaçadas de 0,50 metros entre si. Precedendo a semeadura, as sementes de soja foram tratadas com o fungicida carbendazim + thiram $(200 \mathrm{~mL}$ para $100 \mathrm{~kg}$ de sementes) e o inseticida fipronil (200 $\mathrm{mL}$ para $100 \mathrm{~kg}$ de sementes), além do uso de inoculante líquido, na dose de $200 \mathrm{~mL}$ para 100 $\mathrm{kg}$ de sementes. A semeadura foi realizada mecanicamente depositando-se 16 sementes por metro, a fim de obter uma população final de 320 mil plantas $\mathrm{ha}^{-1}$, de acordo com a recomendação para esta cultivar. A adubação no sulco de semeadura foi realizada com a aplicação de $400 \mathrm{~kg} \mathrm{ha}^{-1}$, do formulado 02-2018.

$\mathrm{Na}$ dessecação foram adotados $1296 \mathrm{~g}$ $\mathrm{ha}^{-1}$ de glyphosate, sendo a aplicação realizada com pulverizador costal pressurizado $\left(\mathrm{CO}_{2}\right)$ dotado de barra com cinco pontas tipo leque XR-110.03, espaçadas 0,5 metros entre si, sob pressão de 20 PSI. Estas condições de aplicação proporcionaram volume de pulverização de $100 \mathrm{~L}$ de calda $\mathrm{ha}^{-1}$. Nas aplicações em pós-emergência, usou-se o mesmo equipamento com a mesma calibração.

$\mathrm{Na}$ cultivar transgênica, os tratamentos com controle químico em pós-emergência empregou-se o herbicida glyphosate, adotandose a mesma dosagem utilizada nos tratamentos de dessecação pré-semeadura; para a variedade convencional, nos tratamentos com controle químico foram adotados os seguintes herbicidas em associação: imazethapyr $(30 \mathrm{~g}$ $\left.\mathrm{ha}^{-1}\right)+$ lactofen $\left(84 \mathrm{~g} \mathrm{ha}^{-1}\right)+$ chlorimuron-ethyl (80 $\mathrm{g} \mathrm{ha}^{-1}$ ), com posterior aplicação (uma semana) do graminicida haloxyfop-methyl, na dose de $72 \mathrm{~g} \mathrm{ha}^{-1}$.
O controle de pragas e doenças foi realizado de acordo com as recomendações da Embrapa (2006). A partir do décimo dia após a emergência da soja, todas as parcelas foram mantidas capinadas, para que não houvesse nenhum tipo de interferência das plantas daninhas, exceto as parcelas testemunhas sem manejo.

As variáveis avaliadas durante a realização do ensaio foram: altura das plantas na ocasião da colheita, altura de inserção da $1^{a}$ vagem, número de vagens com um, dois e três grãos, número de vagens por planta, massa de cem grãos e rendimento de grãos, corrigido para $13 \%$ de umidade. Todos os dados foram submetidos à análise de variância e na detecção de efeito significativo entre os fatores testados ou entre os níveis de cada fator, aplicou-se o teste de comparação de médias de Tukey com $5 \%$ de significância $(\alpha \leq 0,05)$.

\section{Resultados e discussão}

A época de dessecação pré-semeadura só influenciou a altura das plantas de soja na colheita nos tratamentos em que não receberam nenhum tipo de manejo em pós-emergência (Tratamentos 01 e 07), seja a variedade transgênica ou convencional, sendo que a dessecação em sistema "aplique-plante" (AP) proporcionou as maiores alturas de plantas nestes tratamentos, quando comparados ao sistema de manejo antecipado (MA), realizado 15 antes da semeadura (Tabela 02). Esta diferença na altura final das plantas pode ser explicada pelo grau de infestação de plantas daninhas que ocorreu no sistema MA, devido ao novo fluxo de plantas daninhas fazendo com que houvesse maior competição inicial, e, portanto, repercutindo nesta variável.

Vale ressaltar que dados obtidos por Constantin et al. (2009) foram divergentes aos verificados neste trabalho, onde o tratamento com sistema AP foi responsável pela redução na altura da soja na ocasião da colheita. Estes 
autores explicam que nas áreas onde se adota $o$ sistema AP, geralmente, o desenvolvimento inicial da soja é sob grande quantidade de biomassa e intenso sombreamento, o que resulta em estiolamento das plantas. Vale ressaltar no presente trabalho, que na ocasião da dessecação AP, havia grande quantidade de palhada de milho, o que evitou altas densidades de plantas daninhas, fazendo com que não ocorressem condições favoráveis ao estiolamento.
Cita-se se ainda, com relação ao trabalho realizado por Constantin et al. (2009), que no sistema MA foi realizada uma aplicação de um herbicida de contato no dia da semeadura, o que resultou em eliminação das novas plantas daninhas emergidas, fazendo com que não houvesse competição inicial. Esta aplicação não foi adotada no presente trabalho.

Tabela 02. Altura de plantas na colheita e inserção de $1^{a}$ vagem (A.I. $1^{\underline{a}} \mathrm{~V}$.) em soja submetidas a diferentes épocas de dessecação e manejos pós-emergente. Rio Verde - GO, 2008/2009.

\begin{tabular}{|c|c|c|c|c|c|c|c|}
\hline \multirow{3}{*}{ Manejo Pós-emergente } & \multicolumn{4}{|c|}{ Altura de plantas colheita } & \multicolumn{3}{|c|}{ A.I. $1^{\mathrm{a}} \mathrm{V}$. } \\
\hline & \multicolumn{4}{|c|}{ Época de dessecação } & \multicolumn{3}{|c|}{ Época de dessecação } \\
\hline & \multicolumn{2}{|c|}{$15 \mathrm{DAS}$} & \multicolumn{2}{|c|}{$1 \mathrm{DAS}$} & \multicolumn{2}{|c|}{15 DAS } & $1 \mathrm{DAS}$ \\
\hline 1. $\mathrm{ST}^{*}$, sem pós e com capina & 76,32 & $\mathrm{~B}$ a & 83,07 & A a & 27,75 & $\mathrm{~A} \mathrm{a}$ & $27,85 \mathrm{~A} \mathrm{ab}$ \\
\hline 2. $\mathrm{ST}^{*}$, sem pós e sem capina & 75,75 & A a & 78,45 & A a & 27,57 & A a & $26,60 \mathrm{~A} \mathrm{ab}$ \\
\hline 3. ST", com pós aos $15 \mathrm{DAE}$ & 77,47 & $\mathrm{~A}$ a & 78,07 & A a & 22,10 & $\mathrm{Ab}$ & $24,67 \mathrm{~A} \mathrm{ab}$ \\
\hline 4. $\mathrm{ST}^{*}$, com pós aos $30 \mathrm{DAE}$ & 73,12 & A a & 78,25 & A a & 24,90 & $\mathrm{~A} a b$ & $26,85 \mathrm{~A} \mathrm{ab}$ \\
\hline 5. $\mathrm{ST}^{*}$, com pós aos 15 e $30 \mathrm{DAE}$ & 76,00 & $\mathrm{~A}$ a & 77,30 & A a & 25,17 & $\mathrm{~A} a \mathrm{~b}$ & $25,35 \mathrm{~A} \mathrm{ab}$ \\
\hline 6. $\mathrm{SC}^{* *}$, com pós & 70,67 & $\mathrm{~A} \mathrm{a}$ & 68,67 & $\mathrm{Ab}$ & 24,10 & $\mathrm{~A} a b$ & $23,82 \mathrm{~A} \mathrm{~b}$ \\
\hline 7. $\mathrm{SC}^{* *}$, sem pós e com capina & 73,52 & $\mathrm{~B}$ a & 78,77 & A a & 27,60 & A a & $28,00 \mathrm{~A} \mathrm{a}$ \\
\hline $\mathrm{CV}(\%)$ & \multicolumn{4}{|c|}{6,85} & \multicolumn{3}{|c|}{10,41} \\
\hline DMS linha & \multicolumn{4}{|c|}{5,17} & \multicolumn{3}{|c|}{2,67} \\
\hline DMS coluna & \multicolumn{4}{|c|}{7,85} & \multicolumn{3}{|c|}{4,06} \\
\hline
\end{tabular}

"Soja transgênica;" Soja convencional. Médias seguidas pela mesma letra, maiúscula na linha e minúscula na coluna, não diferem entre si pelo teste de Tukey a 5\% de probabilidade

Com relação aos diferentes manejos pós-emergentes empregados, apenas o tratamento com herbicidas utilizados em soja convencional causou redução na taxa de crescimento da soja quando a dessecação foi realizada em sistema AP. Estes dados corroboram com os observados por Barroso et al. (2008), onde a associação entre os herbicidas lactofen + chlorimuron-ethyl + haloxyfop-methyl também causaram menor crescimento das plantas de soja.

A avaliação do efeito dos manejos herbicidas sobre altura de inserção da primeira vagem na soja é extremamente importante, pois esta tem influência direta sobre a sua produtividade (Nepomuceno et al., 2007); em geral, quanto menor a altura de inserção de vagem, maiores são os potenciais de perdas de rendimento no momento da colheita, pois à plataforma de corte da colheitadeira trabalha a uma altura mínima do solo. A época em que foi realizado o manejo de plantas daninhas em présemeadura não influenciou a altura de inserção de primeira vagem (Tabela 02).

Verifica-se nas plantas que foram submetidas ao sistema de MA de plantas daninhas em pré-semeadura uma maior inserção de vagem nos tratamentos em que não houve adoção de controle químico em pós- 
emergência. Entretanto, estes tratamentos diferiram apenas na soja transgênica com aplicação de glyphosate aos 15 após a emergência. No sistema AP, o tratamento que causou maior redução na altura de inserção da primeira vagem foi o com soja convencional com adoção de herbicidas em pós-emergência. Estes resultados corroboram com os observados por Corrêa \& Alves (2009), onde estes autores citam esta paralisação no crescimento em função da fitointoxicação provocadas por estes herbicidas.

Avaliando os componentes de rendimento da soja, foram determinados o número de vagens por planta contendo um, dois e três grãos, quando esta submetidas aos diferentes manejos em pós-emergência, sendo estes resultados expostos nas Tabelas 03 e 04 . A época da dessecação não influenciou o número de vagens por planta com um grão, sendo esta característica influenciada apenas pelos diferentes manejos adotados em pósemergência.

Verifica-se que quando a dessecação foi realizada 15 dias antes da semeadura, o tratamento que apresentou menor número de vagens com um grão foi à testemunha sem manejo em pós-emergência. A competição com plantas daninhas pode afetar diversos componentes de rendimento da cultura da soja, fazendo com que a produção desta cultura seja reduzida em quantidade e qualidade (Silva et al., 2008).

Avaliando-se o número de vagens com dois grãos, não foi verificado nenhum efeito tanto da época de dessecação quanto dos manejos realizados em pós-emergência. Este fato de não se observar nenhuma diferença no número de vagens com dois grãos por planta, pode estar relacionado à características genéticas desta variedade que produz a maior parte de suas vagens com este número de grãos (Guimarães et al., 2008).

Tabela 03. Número de vagens com um (NV1G) e dois grãos (NV2G) em plantas de soja submetidas a diferentes épocas de dessecação e manejos pós-emergente. Rio Verde - GO, 2008/2009.

\begin{tabular}{|c|c|c|c|c|c|c|c|}
\hline \multirow{3}{*}{ Manejo Pós-emergente } & \multicolumn{3}{|c|}{ NV1G } & \multicolumn{4}{|c|}{$\mathrm{NV} 2 \mathrm{G}$} \\
\hline & \multicolumn{3}{|c|}{ Época de dessecação } & \multicolumn{4}{|c|}{ Época de dessecação } \\
\hline & $15 \mathrm{DAS}$ & \multicolumn{2}{|c|}{$1 \mathrm{DAS}$} & \multicolumn{2}{|c|}{$15 \mathrm{DAS}$} & \multicolumn{2}{|c|}{$1 \mathrm{DAS}$} \\
\hline 1. ST", sem pós e com capina & $10,37 \mathrm{~A} \mathrm{ab}$ & 11,62 & $\mathrm{~A} \mathrm{a}$ & 42,62 & $\overline{\mathrm{A} \mathrm{a}}$ & 35,12 & $\overline{\mathrm{A} \mathrm{a}}$ \\
\hline 2. $\mathrm{ST}^{*}$, sem pós e sem capina & $7,50 \mathrm{~A} \mathrm{~b}$ & 8,25 & $\mathrm{~A}$ a & 28,00 & A a & 26,50 & A a \\
\hline 3. $\mathrm{ST}^{*}$, com pós aos $15 \mathrm{DAE}$ & $11,50 \mathrm{~A} \mathrm{ab}$ & 12,12 & $\mathrm{~A} \mathrm{a}$ & 40,87 & A a & 35,87 & $\mathrm{~A}$ a \\
\hline 4. $\mathrm{ST}^{*}$, com pós aos $30 \mathrm{DAE}$ & $11,62 \mathrm{~A} \mathrm{ab}$ & 11,50 & A a & 40,75 & A a & 34,75 & A a \\
\hline 5. $\mathrm{ST}^{*}$, com pós aos 15 e $30 \mathrm{DAE}$ & $13,12 \mathrm{~A} \mathrm{ab}$ & 13,00 & $\mathrm{~A}$ a & 38,12 & $\mathrm{~A} \mathrm{a}$ & 35,62 & $\mathrm{~A}$ a \\
\hline 6. $\mathrm{SC}^{* *}$, com pós & $12,25 \mathrm{~A} \mathrm{ab}$ & 10,62 & A a & 40,25 & $\mathrm{~A}$ a & 38,12 & $\mathrm{~A}$ a \\
\hline 7. $\mathrm{SC}^{* *}$, sem pós e com capina & $14,25 \mathrm{~A} \mathrm{a}$ & 11,62 & $\mathrm{~A} \mathrm{a}$ & 40,37 & $\mathrm{~A} \mathrm{a}$ & 37,37 & $\mathrm{~A} \mathrm{a}$ \\
\hline $\mathrm{CV}(\%)$ & \multicolumn{3}{|c|}{35,12} & \multicolumn{4}{|c|}{28,37} \\
\hline DMS linha & \multicolumn{3}{|c|}{3,97} & \multicolumn{4}{|c|}{10,35} \\
\hline DMS coluna & \multicolumn{3}{|c|}{6,02} & \multicolumn{4}{|c|}{15,71} \\
\hline
\end{tabular}

* Soja transgênica; ** Soja convencional. Médias seguidas pela mesma letra, maiúscula na linha e minúscula na coluna, não diferem entre si pelo teste de Tukey a 5\% de probabilidade

O número de vagens com três grãos e número total de vagens por planta não sofreram influência da época de dessecação présemeadura da soja (Tabela 04). O resultado 
obtido para o número de vagens total, corrobora com os observados por Constantin et al. (2009) na média de cinco ensaios, que influência da época em que é realizada a dessecação pré-semeadura, quando se utiliza o concluíram que esta variável não sofre herbicida glyphosate.

Tabela 04. Número de vagens com três grãos (NV3G) e número de vagens (NVT) por planta de soja submetidas à diferentes épocas de dessecação e manejos pós-emergente. Rio Verde - GO, $2008 / 2009$.

\begin{tabular}{|c|c|c|c|c|c|c|c|c|}
\hline \multirow{3}{*}{ Manejo Pós-emergente } & \multicolumn{4}{|c|}{ NV3G } & \multicolumn{4}{|c|}{ NVT } \\
\hline & \multicolumn{4}{|c|}{ Época de dessecação } & \multicolumn{4}{|c|}{ Época de dessecação } \\
\hline & \multicolumn{2}{|c|}{$15 \mathrm{DAS}$} & \multicolumn{2}{|c|}{$1 \mathrm{DAS}$} & \multicolumn{2}{|c|}{$15 \mathrm{DAS}$} & \multicolumn{2}{|c|}{$1 \mathrm{DAS}$} \\
\hline 1. $\mathrm{ST}^{*}$, sem pós e com capina & 3,62 & $\mathrm{~A} \mathrm{a}$ & 2,62 & $\mathrm{~A} \mathrm{a}$ & $\overline{57,62}$ & $\overline{\mathrm{A} \mathrm{a}}$ & 49,37 & $\overline{\mathrm{A} \mathrm{a}}$ \\
\hline 2. ST", sem pós e sem capina & 2,62 & $\mathrm{~A} \mathrm{a}$ & 1,75 & $\mathrm{~A}$ a & 38,12 & $\mathrm{~A} \mathrm{a}$ & 36,50 & A a \\
\hline 3. $\mathrm{ST}^{*}$, com pós aos $15 \mathrm{DAE}$ & 3,62 & A a & 3,25 & $\mathrm{~A}$ a & 56,00 & $\mathrm{~A} \mathrm{a}$ & 51,25 & A a \\
\hline 4. ST*, com pós aos $30 \mathrm{DAE}$ & 3,87 & A a & 2,87 & A a & 56,25 & A a & 49,12 & A a \\
\hline 5. $\mathrm{ST}^{*}$, com pós aos 15 e $30 \mathrm{DAE}$ & 2,87 & $\mathrm{~A} \mathrm{a}$ & 3,50 & $\mathrm{~A} \mathrm{a}$ & 54,12 & $\mathrm{~A} \mathrm{a}$ & 52,12 & $\mathrm{~A} \mathrm{a}$ \\
\hline 6. SC ${ }^{* *}$, com pós & 4,75 & $\mathrm{~A} \mathrm{a}$ & 3,12 & $\mathrm{~A}$ a & 57,25 & $\mathrm{~A} \mathrm{a}$ & 51,87 & A a \\
\hline 7. SC ${ }^{* *}$, sem pós e com capina & 3,00 & $\mathrm{~A} \mathrm{a}$ & 3,37 & $\mathrm{~A} \mathrm{a}$ & 57,62 & $\mathrm{~A} \mathrm{a}$ & 52,37 & A a \\
\hline $\mathrm{CV}(\%)$ & \multicolumn{4}{|c|}{52,07} & \multicolumn{4}{|c|}{28,14} \\
\hline DMS linha & \multicolumn{4}{|c|}{1,69} & \multicolumn{4}{|c|}{14,36} \\
\hline DMS coluna & \multicolumn{4}{|c|}{2,57} & \multicolumn{4}{|c|}{21,80} \\
\hline
\end{tabular}

* Soja transgênica; ** Soja convencional. Médias seguidas pela mesma letra, maiúscula na linha e minúscula na coluna, não diferem entre si pelo teste de Tukey a 5\% de probabilidade

Os diferentes manejos utilizados em pós-emergência também não afetaram o número de vagens por planta, sendo que resultados semelhantes foram observados por Oliveira Neto et al. (2009). Estes resultados demonstram que a determinação do número de vagens por planta está intimamente ligada ao potencial genético de cada variedade, sendo esta variável pouco influenciada pela utilização destes herbicidas, que são seletivos a esta cultura.

Os resultados obtidos para avaliação dos tratamentos sobre a massa de cem grãos estão expostos na Tabela 05. Verifica-se que apenas a testemunha sem nenhum manejo em pós-emergência da variedade de soja transgênica teve redução na massa dos grãos, sendo este efeito mais intenso quando se realizou o sistema de dessecação com MA (15 dias antes da semeadura). Constantin et al. (2009) verificaram tendência contrária a observada neste trabalho, onde massa de cem grãos de soja foi reduzida quando a semeadura foi realizada logo após a aplicação do glyphosate.

A redução na massa de cem grãos ocorre principalmente por fatores ligados a competição com as plantas daninhas, onde as plantas direcionam seus assimilados produzidos para o seu crescimento, resultando em um déficit para o enchimento do órgão vegetativo (Taiz \& Zeiger, 2006). Além disso, à convivência com as plantas daninhas faz com que se crie um ambiente com alta umidade, o que favorece o surgimento de patógenos nas vagens e grãos, resultando em depreciação na massa destes (Gazziero et al., 2004).

A produtividade da soja foi superior quando se realizou o sistema aplique-plante em comparação com o manejo antecipado, nos Tratamentos 01 e 02. Ressalta-se que a redução na produtividade da soja ocorreu devido a um novo fluxo de plantas daninhas, emergidas quando a dessecação foi realizada 15 dias antes 
da semeadura, lembrando que todas as parcelas foram mantidas capinadas após 10 dias da emergência, podendo ser um indicativo de que nas referidas condições a soja pode ter um período anterior à interferência menor do que se tem relatado (Spadotto et al., 1994; Meschede et al., 2002).

Tabela 05. Massa de cem grãos $(\mathrm{M} 100 \mathrm{G})$ e produtividade $\left(\mathrm{kg} \mathrm{ha}^{-1}\right)$ de soja submetidas à diferentes épocas de dessecação e manejos pós-emergente. Rio Verde - GO, 2008/2009.

\begin{tabular}{|c|c|c|c|c|c|c|c|c|}
\hline \multirow{3}{*}{ Manejo Pós-emergente } & \multicolumn{4}{|c|}{ M100G } & \multicolumn{4}{|c|}{ Produtividade } \\
\hline & \multicolumn{4}{|c|}{ Época de dessecação } & \multicolumn{4}{|c|}{ Época de dessecação } \\
\hline & \multicolumn{2}{|c|}{$15 \mathrm{DAS}$} & \multicolumn{2}{|c|}{$1 \mathrm{DAS}$} & \multicolumn{2}{|c|}{$15 \mathrm{DAS}$} & \multicolumn{2}{|c|}{$1 \mathrm{DAS}$} \\
\hline 1. ST", sem pós e com capina & 12,57 & A a & 13,14 & $\mathrm{~A} \mathrm{a}$ & 2923,61 & $\mathrm{~B}$ a & 3548,34 & A a \\
\hline 2. $\mathrm{ST}^{*}$, sem pós e sem capina & 10,25 & $\mathrm{~B} \mathrm{~b}$ & 11,32 & $\mathrm{Ab}$ & 1683,50 & $\mathrm{~B} \mathrm{~b}$ & 2436,74 & $\mathrm{Ab}$ \\
\hline 3. $\mathrm{ST}^{*}$, com pós aos $15 \mathrm{DAE}$ & 13,54 & $\mathrm{~A} \mathrm{a}$ & 14,01 & A a & 3659,81 & A a & 3620,07 & A a \\
\hline 4. $\mathrm{ST}^{*}$, com pós aos $30 \mathrm{DAE}$ & 13,59 & $\mathrm{~A} \mathrm{a}$ & 13,43 & A a & 3313,01 & $\mathrm{~A} \mathrm{a}$ & 3514,81 & A a \\
\hline 5. $\mathrm{ST}^{*}$, com pós aos 15 e $30 \mathrm{DAE}$ & 13,47 & $\mathrm{~A} \mathrm{a}$ & 13,09 & A a & 3376,60 & A a & 3470,06 & A a \\
\hline 6. SC ${ }^{* *}$, com pós & 13,50 & $\mathrm{~A} \mathrm{a}$ & 13,89 & A a & 3468,44 & $\mathrm{~A} \mathrm{a}$ & 3473,90 & A a \\
\hline 7. SC ${ }^{* *}$, sem pós e com capina & 13,28 & $\mathrm{~A} \mathrm{a}$ & 14,19 & $\mathrm{~A} \mathrm{a}$ & 3026,57 & $\mathrm{~A} \mathrm{a}$ & 3506,14 & A a \\
\hline CV (\%) & \multicolumn{4}{|c|}{7,71} & \multicolumn{4}{|c|}{16,68} \\
\hline DMS linha & \multicolumn{4}{|c|}{1,01} & \multicolumn{4}{|c|}{540,43} \\
\hline DMS coluna & \multicolumn{4}{|c|}{1,53} & \multicolumn{4}{|c|}{820,50} \\
\hline
\end{tabular}

* Soja transgênica; ** Soja convencional. Médias seguidas pela mesma letra, maiúscula na linha e minúscula na coluna, não diferem entre si pelo teste de Tukey a $5 \%$ de probabilidade

Uma alternativa para que assegurar que não haja redução na produção da soja em função deste novo fluxo de infestantes no sistema MA é a aplicação de herbicidas de contato próximo a semeadura, pois estes vão ter alta eficácia devido a população de daninhas presentes estar em estádios de crescimento iniciais (Oliveira Jr. et al., 2006; Procópio et al., 2006) ou utilizar um herbicida pré-emergente que controle este novo fluxo evitando desta forma a mato-competição inicial (Oliveira Jr. et al., 2002). Com relação aos manejos utilizados em pós-emergência, verificou-se que todos os tratamentos apresentaram-se seletivos para a soja. O Tratamento 02 (sem nenhum controle pósemergente) foi o único a causar reduções no rendimento da soja, demonstrando então os malefícios provocados pela competição com as plantas daninhas.

\section{Conclusão}

A competição exercida pelo novo fluxo de plantas daninhas emergidas quando a dessecação foi realizada antecipadamente foi mais prejudicial à produtividade das cultivares de soja em alguns tratamentos em relação ao sistema aplique-plante.

Com relação aos manejos utilizados em pós-emergência, tanto para soja convencional (BRS-GO Luziânia) quanto transgênica (BRSGO Luziânia $R^{\circledR}{ }^{\circledR}$ ), verificou-se redução na produtividade apenas nos tratamentos sem adoção de nenhum método de controle, demonstrando a alta seletividade das cultivares apresentam aos herbicidas testados. 


\section{Agradecimentos}

Agradecimento a Cooperativa Agroindustrial dos Produtores Rurais do Sudoeste Goiano - COMIGO, por todo auxílio disponibilizado na condução deste trabalho.

\section{Referências}

ARRUDA, J.S. et al. Nodulação e fixação do nitrogênio em soja tratada com sulfentrazone. Pesquisa Agropecuária Brasileira, v.36, n.2, p.325-330, 2001.

BARROSO, A.L.L. et al. Seletividade de associações herbicidas pós-emergentes em variedade de soja precoce. Revista Brasileira de Herbicidas, v.7, n.2, p.36-42, 2008.

CONSTANTIN, J. et al. Sistemas de manejo de plantas daninhas no desenvolvimento e na produtividade da soja. Bragantia, v.68, n.1, p.125-135, 2009.

CORRÊA, M.J.P.; ALVES, P.L.C.A. Eficácia de herbicidas aplicados em pós-emergência na cultura da soja convencional e transgênica. Planta Daninha, v.27, n.espec., p.1035-1046, 2009.

DVORANEN, E.C. et al. Nodulação e crescimento de variedades de soja rr sob aplicação de glyphosate, fluazifop-p-butyl e fomesafen. Planta Daninha, v.26, n.3, p. 619625, 2008.

EMBRAPA. Centro Nacional de Pesquisa de Soja. Recomendações técnicas para a cultura da soja na Região Central do Brasil 2007. Londrina: EMBRAPA-CNPSo. Sistemas de produção 11. Embrapa Soja: 2006. $225 \mathrm{p}$.

FREITAS, S.P. et al. Manejo de plantas daninhas no plantio direto da soja (Glycine max) sobre o milheto (Pennisetum maximum). Planta Daninha, v.24, n.3, p.481-487, 2006.
GAZZIERO, D.L.P.; VARGAS, L.; ROMAN, E.S. Manejo e controle de plantas daninhas em soja. In: VARGAS, L.; ROMAN, E. S. Manual de manejo e controle de plantas daninhas. Bento Gonçalves: Embrapa Uva e Vinho, 2004. p.595-635.

GUIMARÃES, F.S. et al. Cultivares de soja [Glycyne max (L.) Merrill] para cultivo de verão na região de Lavras-MG. Ciência e Agrotecnologia., v.32, n.4, p.1099-1106, 2008.

MESCHEDE, D.K. et al. Período crítico de interferência de Euphorbia heterophylla na cultura da soja sob baixa densidade de semeadura. Planta Daninha, v.20, n.3, p.381387, 2002.

NEPOMUCENO, $M$. et al. Períodos de interferência das plantas daninhas na cultura da soja nos sistemas de semeadura direta e convencional. Planta Daninha, v.25, n.1, p.43-50, 2007.

OLIVEIRA JR, R.S. et al. Interação entre sistemas de manejo e de controle de plantas daninhas em pós-emergência afetando o desenvolvimento e a produtividade da soja. Planta Daninha, v.24, n.4, p.721-732, 2006.

OLIVEIRA JR, R.S. et al. Controle de plantas daninhas e seletividade do diclosulam aplicado em pré-emergência na cultura da soja. Revista Brasileira de Herbicidas, v.3, n.1, p.69-74, 2002.

OLIVEIRA NETO, M.E.F. et al. Seletividade de herbicidas pós-emergentes aplicados na soja geneticamente modificada. Planta Daninha, v.27, n.2, p.345-352, 2009.

PETTER, F.A. et al. Manejo de herbicidas na cultura da soja Roundup Ready ${ }^{\circledR}$. Planta Daninha, v.25, n.3, p.557-566, 2007.

PROCÓPIO, S.O. et al. Efeitos de dessecantes no controle de plantas daninhas na cultura da soja. Planta Daninha, v.24, n.1, p.193-197, 2006. 
SILVA, A.F. et al. Densidades de plantas daninhas e épocas de controle sobre os componentes de produção da soja. Planta Daninha, v.26, n.1, p.65-71, 2008.

SPADOTTO, C.A. et al. Determinação do período crítico para prevenção da interferência de plantas daninhas na cultura de soja: uso do modelo "Broken-Stick". Planta Daninha, v.12, n.2, p.59-62, 1994.

TAIZ, L.; ZEIGER, E. Plant physiology. 3.ed. Sunderland: Sinauer Associates, 2006. p.705. 